\title{
Aplicação foliar de silício na produtividade e sanidade de cultivares de soja
}

\author{
Foliar spraying with silicon in the yield and health of soybean cultivars
}

\section{Renato Anastácio Guazina ${ }^{1}$, Gustavo de Faria Theodoro²*, Sofia Michele Muchalak ${ }^{3}$ e Luis Gustavo Amorim Pessoa ${ }^{4}$}

${ }^{1}$ Universidade Federal da Grande Dourados, Dourados, MS, Brasil.

2Universidade Federal de Mato Grosso do Sul, Campo Grande, MS, Brasil. * Autor para correspondência: gustavo.theodoro@ufms.br. ${ }^{3}$ Raízen, Araraquara, SP, Brasil.

${ }^{4}$ Universidade Federal de Mato Grosso do Sul, Chapadão do Sul, MS, Brasil.

Submissão:26/07/2017 | Aceite: 25/02/2019

\begin{abstract}
RESUMO
A soja é uma das principais espécies agrícolas cultivadas no Brasil, porém, pode ter a produtividade reduzida pela incidência de pragas e doenças. O objetivo deste trabalho foi avaliar o efeito da aplicação de silício em diferentes estádios fenológicos da soja na severidade da ferrugem asiática (FAS), população de lagartas desfolhadoras e produtividade. $O$ experimento foi conduzido no município de Chapadão do Sul, MS, durante a safra 2012/2013, em blocos casualizados, com cinco repetições e em esquema fatorial (2x5). Os fatores foram: duas cultivares de soja (Anta 82 RR e CD 2737 RR) e cinco tratamentos para o manejo da FAS (T1- testemunha negativa; T2- silicato de alumínio em R1 + R4; T3- silicato de alumínio em V5 + R1 + R4; T4- silicato de alumínio em V5 + R1 + R4 + R5.1; e T5- testemunha positiva: trifloxistrobina + protioconazol em R1 + R4). A severidade da FAS foi estimada periodicamente para 0 cálculo da área abaixo da curva de progresso da doença (AACPD) e a desfolha e a produtividade foram avaliadas ao final do ciclo da cultura. $O$ monitoramento da população de lagartas desfolhadoras foi realizado semanalmente por meio de pano de batida. A aplicação de silicato de alumínio reduziu a severidade da FAS e a AACPD em relação à testemunha, porém os valores foram significativamente maiores que os observados para a testemunha positiva. Houve incremento da produtividade de grãos quando foram realizadas três e quatro aplicações de silicato de alumínio e não se verificou redução do nível populacional de lagartas desfolhadoras.
\end{abstract}

PALAVRAS-CHAVE: silicato de alumínio, Phakopsora pachyrhizi, Anticarsia gemmatalis, Chrysodeixis includens.

\begin{abstract}
Soybean is one of the main agricultural species cultivated in Brazil, but it may have reduced yield due to the incidence of pests and diseases. This study aimed to evaluate the effect of silicon spray at different soybean phenological stages on the severity of Asian rust (AR), the soybean caterpillar population, and the yield of soybean. The experiment was conducted in the 2012/2013 crop season through a randomized complete block with five replications and factorial scheme $(2 \times 5)$. The factors were two soybean cultivars (Anta 82 RR and CD $2737 \mathrm{RR}$ ) and five treatments for AR management (T1- negative control; T2aluminum silicate in R1 + R4; T3- aluminum silicate in V5 + R1 + R4; T4- aluminum silicate in V5 + R1 + R4 + R5.1; and T5- positive control: trifloxystrobin + prothioconazole in R1 + R4). Defoliation, disease severity, area under the disease progress curve (AUDPC) and yield were evaluated. Soybean caterpillar population was monitored weekly using a beating sheet. Sprays of aluminum silicate reduced the severity of AR and AUDPC in relation to the control, but it was less effective than the positive control. Grain yield increased when three and four aluminum silicate sprays were performed, and the population level of soybean caterpillars was not reduced by silicon.
\end{abstract}

KEYWORDS: Aluminum silicate, Phakopsora pachyrhizi, Anticarsia gemmatalis, Chrysodeixis includens.

\section{INTRODUÇÃO}

A soja [Glycine max (L.) Merrill] é uma das mais importantes oleaginosas cultivadas no mundo, principalmente devido aos elevados teores de proteína (40\%), óleo (20\%) e pelo alto rendimento de grãos. 
No Brasil a produtividade média, na safra $2016 / 2017$, foi de $3.176 \mathrm{~kg} \mathrm{ha}^{-1}$, com uma produção de $107.614,6$ mil toneladas em aproximadamente $33.878,8$ mil hectares (CONAB 2017). Entretanto, a produtividade da soja pode ser afetada por um conjunto de fatores, sendo que os problemas fitossanitários, como a ocorrência de doenças e insetos pragas, possuem elevada capacidade em limitar o máximo potencial produtivo da cultura, além de poder afetar a qualidade final do produto, quando não manejados eficientemente (HARTMAN et al. 2015).

Atualmente, dentre as inúmeras doenças que podem ocorrer ao longo do ciclo da cultura da soja, destaca-se como a mais severa a ferrugem asiática, cujo agente causal é o fungo Phakopsora pachyrhizi. Esse patógeno ocorre em praticamente todas as regiões produtoras e durante todo o ciclo da cultura, infectando o tecido foliar e dependendo da severidade da doença é capaz de desfolhar completamente a planta (GOELLNER et al. 2010), causando perdas de até 90\% (GODOY et al. 2016). Os insetos pragas que ocorrem na cultura da soja que merecem destaque são os pertencentes ao grupo dos desfolhadores, em especial, a lagarta-da-soja (Anticarsia gemmatalis, Lepidoptera: Noctuidae), a lagarta-falsa-medideira (Chrysodeixis includens, Lepidoptera: Noctuidae) e o complexo de lagartas do gênero Spodoptera (S. cosmioides, $S$. eridania e $S$. frugiperda, Lepidoptera: Noctuidae) espécies que causam danos que vão desde a desfolha parcial até a destruição completa da planta quando o nível populacional é elevado (FREITAS BUENO et al. 2011).

Para minimizar os danos causados tanto pela ferrugem asiática quanto pelas lagartas desfolhadoras é fundamental adotar medidas de controle de forma integrada. No entanto, apesar do manejo integrado de pragas e doenças preconizar a utilização de várias medidas de controle (PESHIN \& DHAWAN 2009), é notório que a principal medida utilizada pelos sojicultores ainda é somente o controle químico por meio de fungicidas e inseticidas. Um dos riscos da utilização de apenas estes produtos é a seleção de biótipos resistentes, como tem sido observado nos últimos anos a perda de eficiência dos fungicidas triazol, estrobilurina (GODOY et al. 2016) e carboxamida no combate de P. pachyrhizi (FRAC 2017). Casos de resistência de insetos pragas aos inseticidas também têm sido observados em diversas localidades, inclusive com C. includens principalmente aos inseticidas piretroides (SOSA-GÓMEZ \& OMOTO 2012).

A indução de resistência na planta, através da adubação silicatada, tem sido relatada como uma excelente medida de controle tanto de pragas como de doenças em diversas culturas, podendo ser incluída nos programas de manejo integrado (POZZA et al. 2015). Na cultura da soja, a aplicação do silicato de potássio no dossel da cultura, foi capaz de reduzir a severidade da ferrugem asiática (PEREIRA et al. 2009). Em outro experimento, CRUZ et al. (2013) relataram que a redução da severidade da ferrugem em plantas tratadas com silicato de cálcio está associada ao aumento da atividade de enzimas de defesa (quitinases, glucanases e fenilalamina) durante o processo infeccioso. Nesse mesmo patossistema, o uso de silicato de potássio influenciou significativamente o teor de lignina nas folhas de soja, assim, constituindo-se como barreira física à penetração do patógeno (LIMA et al. 2010). Essa barreira aumenta a dureza dos tecidos foliares, reduzindo a qualidade do alimento para os insetos herbívoros, podendo provocar o desgaste de suas mandíbulas (GOUSSAIN et al. 2002) ou alterações na biologia, como prolongamento do período larval e até a mortalidade de adultos, observado em C. includens (SOUZA et al. 2014).

Diante do exposto, o objetivo deste trabalho foi avaliar o efeito da aplicação de silício em diferentes estádios fenológicos da soja na severidade da ferrugem asiática, população de lagartas desfolhadoras e produtividade.

\section{MATERIAL E MÉTODOS}

O experimento foi conduzido na Universidade Federal de Mato Grosso do Sul, Campus de Chapadão do Sul, durante a safra 2012/2013. O delineamento experimental empregado foi em blocos casualizados, com cinco repetições, em esquema fatorial $(2 \times 5)$. Os fatores foram duas cultivares de soja de ciclo indeterminado (Anta $82 \mathrm{RR}$ e CD $2737 \mathrm{RR}$ ) e cinco tratamentos para o manejo da ferrugem asiática (Tabela 1). As parcelas experimentais apresentaram área total de $9,0 \mathrm{~m}^{2}(1,8 \times 5,0 \mathrm{~m})$, sendo as avaliações realizadas na área útil de $3,6 \mathrm{~m}^{2}(0,9 \times 4,0 \mathrm{~m})$.

Os produtos utilizados para o controle da ferrugem asiática foram: silicato de alumínio $\left(20,53 \% \mathrm{Al}_{2} \mathrm{O}_{3}\right.$, $17,43 \% \mathrm{SiO}_{2}, 9,82 \% \mathrm{~S}, 1,31 \% \mathrm{CaO}, 0,34 \% \mathrm{TiO}_{2}, 0,18 \% \mathrm{MgO}, 0,16 \% \mathrm{Fe}_{2} \mathrm{O}_{3}$ e $\left.0,10 \% \mathrm{P}_{2} \mathrm{O}_{5}\right)$ na dose de 3,0 $\mathrm{kg}$ p.c. ha $\mathrm{e}^{-1} \mathrm{e}$ a mistura comercial do fungicida trifloxistrobina + protioconazol $\left(150 \mathrm{~g}\right.$ i.a. $\mathrm{L}^{-1}+175 \mathrm{~g}$ i.a. $\left.\mathrm{L}^{-1}\right)$ na dose de 0,4 L p.c. ha- ${ }^{-1}$ como testemunha positiva. As aplicações foram realizadas no período vespertino, em diferentes estádios fenológicos da cultura (Tabela 1) e por meio de um pulverizador costal pressurizado por $\mathrm{CO}_{2}$, com ponta de jato duplo e plano e calibrado para liberar uma vazão constante de $150 \mathrm{~L} \mathrm{ha}{ }^{-1}$ de calda, a $50 \mathrm{~cm}$ acima do dossel da cultura. 
Tabela 1. Tratamentos e doses aplicados em cultivares de soja para o controle de ferrugem asiática e lagartas desfolhadoras. Chapadão do Sul, MS, safra 2012/2013.

Table 1. Treatments and doses applied to soybean cultivars for the control of Asian soybean rust and soybean caterpillars. Chapadão do Sul, MS, crop season 2012/2013.

\begin{tabular}{llll}
\hline & \multicolumn{1}{c}{ Tratamentos } & $\begin{array}{c}\text { Dosagem } \\
(\mathrm{kg} \mathrm{p.c.} \mathrm{ha-1/L} \mathrm{p.c.} \mathrm{ha-1})\end{array}$ & \multicolumn{1}{c}{ Época de aplicação } \\
\hline 1 & Testemunha negativa & - & - \\
2 & Silicato de alumínio & 3,0 & $\mathrm{R} 1+\mathrm{R} 4$ \\
3 & Silicato de alumínio & 3,0 & $\mathrm{~V} 5+\mathrm{R} 1+\mathrm{R} 4$ \\
4 & $\begin{array}{l}\text { Silicato de alumínio } \\
\text { Testemunha positiva }\end{array}$ & 3,0 & $\mathrm{~V} 5+\mathrm{R} 1+\mathrm{R} 4+\mathrm{R} 5.1$ \\
\hline & (trifloxistrobina + protioconazol) & 0,4 & $\mathrm{R} 1+\mathrm{R} 4$
\end{tabular}

${ }^{*}$ As dosagens utilizadas seguiram as recomendações dos fabricantes.

As avaliações da severidade da doença foram iniciadas a partir do surgimento dos primeiros sintomas no estádio fenológico R5.3 e repetidas em R5.4 e R5.5. Em todas as avaliações, dez plantas foram escolhidas ao acaso na área útil de cada parcela e, em cada planta, foram coletadas duas folhas localizadas na metade inferior e superior da planta. Para determinar a porcentagem de severidade em cada folha, utilizou-se a escala diagramática de GODOY et al. (2006). As notas individuais atribuídas a cada metade da planta foram corrigidas matematicamente, conferindo-Ihes diferentes pesos, gerando uma nota final de acordo com a seguinte equação: severidade $=($ severidade inferior $\times 0,35)+($ severidade na metade superior $x$ 0,65), conforme metodologia proposta por MADALOSSO et al. (2010). Com os dados de severidade foi determinada a área abaixo da curva de progresso da doença (AACPD) (CAMPBELL \& MADDEN 1990).

Foi determinada a porcentagem de desfolha em cada parcela, no estádio fenológico R7, por meio da escala diagramática empregada por HIRANO et al. (2010), com seis níveis de desfolha $(5,15,45,65,85$ e $100 \%)$.

Realizaram-se amostragens de lagartas desfolhadoras, com auxílio de pano de batida (STÜRMER et al. 2014), quantificando-se, em cada parcela, os insetos, independentemente do tamanho. A avaliação ocorreu com frequência semanal, iniciando na fase vegetativa (V5) até a completa formação de grãos (R6). O controle químico das lagartas desfolhadoras foi realizado somente quando sua população média, em cada tratamento, era igual ou superior a 20 lagartas por pano de batida, ou seja, quando atingia o nível de controle recomendado (OLIVEIRA \& ROSA 2014). O inseticida utilizado foi a mistura comercial de alfacipermetrina + teflubenzurom (75 g i.a. $\mathrm{L}^{-1}+75 \mathrm{~g}$ i.a. $\mathrm{L}^{-1}$ ) na dose de $200 \mathrm{ml}$ p.c. ha-1, seguindo os mesmos padrões de uso dos demais produtos mencionados anteriormente.

Para avaliação da produtividade de grãos $\left(\mathrm{kg} \mathrm{ha}^{-1}\right)$, colheu-se a produção das plantas da área útil de cada parcela, sendo corrigida a umidade de grãos para $13 \%$.

Os dados obtidos nas avaliações foram submetidos à análise de variância para verificar a significância da interação entre cultivares e os tratamentos para manejo da doença. Em caso de não significância da interação, realizou-se a análise individual de cada fator pelo teste $F$ para o fator cultivar e o teste Scott-Knott para o fator tratamentos para manejo da ferrugem asiática, em nível de significância de $5 \%$.

\section{RESULTADOS E DISCUSSÃO}

Não houve interação entre cultivares e tratamentos em nenhuma das avaliações realizadas. Em relação ao fator cultivar (Tabela 2), verificou-se maior suscetibilidade à ferrugem na segunda e terceira avaliação na cultivar Anta 82 RR. Apesar destas cultivares serem consideradas suscetíveis, houve variação entre elas quanto à reação a $P$. pachyrhizi, corroborando com os resultados obtidos por NAVARINI et al. (2007). De forma semelhante, ao avaliar o sistema de semeadura em linhas cruzadas empregando-se duas cultivares de soja em Chapadão do Sul, MS, LIMA et al. (2012) constataram que a severidade da ferrugem asiática da soja foi maior nas plantas da cultivar Anta $82 \mathrm{RR}$.

Observando o segundo fator (tratamentos para manejo da ferrugem asiática) notou-se, de modo geral, que as plantas que apresentaram as menores severidades da doença foram aquelas que receberam tratamento com fungicida. Em relação aos tratamentos para manejo da ferrugem que tinham silicato de 
alumínio, verificou-se redução significativa na severidade da doença em relação à testemunha (Tabela 2). $\mathrm{Na}$ última avaliação de severidade da doença (R5.5), o tratamento com quatro aplicações de silicato de alumínio (T4) reduziu a severidade da ferrugem quando comparado aos demais tratamentos com silício (T2 e T3), porém, a severidade foi significativamente maior em relação ao tratamento com fungicida (T5).

Tabela 2. Severidade da ferrugem asiática da soja e da área abaixo da curva do progresso da doença (AACPD) em duas cultivares de soja submetidas à aplicações foliares de silício. Chapadão do Sul, MS, safra 2012/2013.

Table 2. Asian soybean rust severity and area under the disease progress curve (AUDPC) in two cultivars submitted to silicon foliar sprays. Chapadão do Sul, MS, crop season 2012/2013.

\begin{tabular}{lcllll}
\hline Fatores & & R5.3 & R5.4 & R5.5 & AACPD \\
\hline \multirow{2}{*}{ Cultivar } & CD 2737 RR & $0,11 \mathrm{a}$ & $0,84 \mathrm{a}$ & $7,57 \mathrm{a}$ & $32,87 \mathrm{a}$ \\
& Anta 82 RR & $0,13 \mathrm{a}$ & $1,07 \mathrm{~b}$ & $8,54 \mathrm{~b}$ & $37,86 \mathrm{~b}$ \\
\hline \multirow{3}{*}{ Tratamentos } & T1* & $0,20 \mathrm{c}$ & $1,23 \mathrm{C}$ & $11,17 \mathrm{~d}$ & $48,41 \mathrm{~d}$ \\
& T2 & $0,15 \mathrm{~b}$ & $1,00 \mathrm{~b}$ & $9,67 \mathrm{c}$ & $41,35 \mathrm{c}$ \\
& T3 & $0,13 \mathrm{~b}$ & $0,94 \mathrm{~b}$ & $8,78 \mathrm{c}$ & $37,81 \mathrm{c}$ \\
& T4 & $0,12 \mathrm{~b}$ & $0,99 \mathrm{~b}$ & $6,76 \mathrm{~b}$ & $31,06 \mathrm{~b}$ \\
& T5 & $0,03 \mathrm{a}$ & $0,63 \mathrm{a}$ & $3,90 \mathrm{a}$ & $18,20 \mathrm{a}$ \\
\hline CV (\%) & & 33,80 & 15,92 & 15,95 & 14,01 \\
\hline
\end{tabular}

Médias seguidas de mesma letra na coluna não diferem entre si pelo teste $\mathrm{F}$ para o fator Cultivar e pelo teste de ScottKnott para o fator Tratamentos, ao nível de $5 \%$ de probabilidade. ${ }^{*} T 1$ : testemunha; T2: silicato de alumínio (R1 + R4); T3: silicato de alumínio (V5 + R1 + R4); T4: silicato de alumínio (V5 + R1 + R4 + R5.1); T5: testemunha positiva trifloxistrobina + protioconazol (R1 + R4).

$\mathrm{Na}$ avaliação da AACPD, a média da cultivar CD 2737 RR foi significativamente $(p<0,05)$ menor em relação a Anta $82 \mathrm{RR}$ (Tabela 2). O silício reduziu a taxa de progresso da doença independentemente do número de aplicações, porém, a maior eficiência foi obtida com quatro aplicações do produto. Isso mostra que apesar do produto a base de silício ser menos eficiente em relação ao fungicida no combate da ferrugem asiática, tem condições de reduzir a severidade e, consequentemente, a AACPD em condições de campo.

Existem relatos sobre a eficiência do uso de silício em diversas culturas agrícolas. SCHURT et al. (2013) observaram redução de até $23 \%$ da área abaixo da curva do progresso da queima das bainhas em plantas de arroz supridas com esse elemento. Resultados semelhantes foram obtidos por MEDEIROS \& PERUCH (2012), em pesquisa com antracnose do maracujazeiro, os quais verificaram que a aplicação de silicato de alumínio proporcionou redução de $82 \%$ na curva de progresso da doença. TEIXEIRA et al. (2008) verificaram que plantas de feijoeiro comum tratadas com silício apresentaram menor severidade de antracnose e mancha angular na safra das "águas", e de crestamento bacteriano na "seca". Possivelmente, essa redução da severidade e da AACPD ocorreu pelo aumento da resistência das plantas proporcionada por esse elemento, através do aumento da lignificação dos tecidos vegetais e, também, da ativação de enzimas que tem função de inibir ou impedir o desenvolvimento do patógeno na planta hospedeira (PEREIRA et al. 2009, POZZA et al. 2015).

$\mathrm{Na}$ avaliação de desfolha (Tabela 3), foi observada menor porcentagem nas parcelas com a cultivar CD 2737 RR, diferindo estatisticamente da Anta 82 RR. A desfolha das plantas que receberam silicato de alumínio foi semelhante da verificada nas plantas que não receberam aplicações (testemunha). A menor porcentagem de desfolha foi observada nas parcelas onde as plantas receberam duas aplicações de fungicida (T5), diferindo estatisticamente dos demais. Há diversos relatos na literatura que demonstram a retenção foliar causada por alguns fungicidas (SILVA et al. 2013) e a desfolha causada pela ferrugem asiática da soja (PELUZIO et al. 2002), que podem explicar os resultados obtidos neste trabalho.

A cultivar CD 2737 RR apresentou maior produtividade em relação a Anta 82 RR (Tabela 3). Quando observado o fator tratamento para manejo da ferrugem asiática, constatou-se que duas aplicações de silicato de alumínio (T2) não proporcionaram aumento na produtividade de grãos, não diferindo da testemunha. Porém, houve incremento de 13 a 16\% (T3 e T4, respectivamente) em relação à testemunha na produtividade quando foram realizadas três e quatro aplicações de silicato de alumínio. A maior produtividade de grãos foi observada no tratamento com fungicida, de $2.778 \mathrm{~kg} \mathrm{ha}^{-1}$ (Tabela 3).

Resultados obtidos por MOREIRA et al. (2010) mostraram que somente a partir da terceira aplicação o silício acumula-se em níveis adequados na planta de soja, promovendo aumento no acúmulo de massa 
seca e produtividade de grãos. CRUSCIOL et al. (2013) relatam que a quatro aplicações de silício promoveram aumento no número de vagens e na produtividade de grãos das culturas da soja, feijão e amendoim.

Tabela 3. Desfolha causada pela ferrugem asiática (\%) e produtividade $\left(\mathrm{kg} \mathrm{ha}^{-1}\right)$ de duas cultivares de soja submetidas à aplicações foliares de silício. Chapadão do Sul, MS, safra 2012/2013.

Table 3. Defoliation caused by asian rust (\%) and yield $\left(\mathrm{kg} \mathrm{ha}^{-1}\right)$ of two soybean cultivars submitted to silicon foliar sprays. Chapadão do Sul, MS, crop season 2012/2013.

\begin{tabular}{lccc}
\hline Fatores & Desfolha (\%) & $\begin{array}{c}\text { Produtividade } \\
\left(\mathrm{kg} \mathrm{ha}^{-1}\right)\end{array}$ \\
\hline Cultivar & CD 2737 RR & $55,8 \mathrm{a}$ & $2.523 \mathrm{a}$ \\
& Anta 82 RR & $61,4 \mathrm{a}$ & $2.362 \mathrm{~b}$ \\
\hline \multirow{3}{*}{ Tratamentos } & T1 & $67,0 \mathrm{~b}$ & $2.160 \mathrm{c}$ \\
& T2 & $67,0 \mathrm{~b}$ & $2.322 \mathrm{c}$ \\
& T3 & $63,0 \mathrm{~b}$ & $2.442 \mathrm{~b}$ \\
& T4 & $59,0 \mathrm{~b}$ & $2.508 \mathrm{~b}$ \\
\hline CV $(\%)$ & T5 & $37,0 \mathrm{a}$ & $2.778 \mathrm{a}$ \\
\hline
\end{tabular}

Médias seguidas de mesma letra na coluna não diferem entre si pelo teste $\mathrm{F}$ para o fator Cultivar e pelo teste de ScottKnott para o fator Tratamentos, ao nível de $5 \%$ de probabilidade. ${ }^{\star} T 1$ : testemunha; T2: silicato de alumínio (R1 + R4); T3: silicato de alumínio (V5 + R1 + R4); T4: silicato de alumínio (V5 + R1 + R4 + R5.1); T5: testemunha positiva trifloxistrobina + protioconazol $(\mathrm{R} 1+\mathrm{R} 4)$.

Prevaleceu a ocorrência de $A$. gemmatalis e $C$. includens, havendo diferenças significativas entre os tratamentos empregados (Tabela 4), independentemente da cultivar. Na terceira avaliação, mesmo com a utilização do silício, verificou-se que o número de lagartas (>20 lagartas) na terceira avaliação justificou o emprego de inseticida nas plantas que receberam todos os tratamentos. Na sexta avaliação, somente não se constatou novamente este aumento populacional em T4. As avaliações que ocorreram após a aplicação de inseticida (Tabela 4) sugerem que houve efeito aditivo no controle das lagartas, pois houve menos lagartas em relação às plantas que receberam silício e inseticida (T2, T3 e T4, quarta avaliação) em relação àquelas que apenas receberam inseticida para o controle de lagartas (T1 e T5, quarta avaliação).

Tabela 4. Número médio de lagartas desfolhadoras por pano de batida em duas cultivares de soja submetidas à aplicações foliares de silício. Chapadão do Sul, MS, safra 2012/2013.

Table 4. Average number of soybean caterpillars per beating sheet in two soybean crops submitted to silicon foliar sprays. Chapadão do Sul, MS, harvest 2012/2013.

\begin{tabular}{|c|c|c|c|c|c|c|c|c|}
\hline \multirow{3}{*}{ Tratamentos } & \multicolumn{8}{|c|}{ Número médio de lagartas/pano de batida } \\
\hline & \multicolumn{8}{|c|}{ Avaliações $^{\star *}$} \\
\hline & $1^{\underline{a}}$ & $2^{\mathrm{a}}$ & $3^{\mathrm{a}}$ & $4^{\mathrm{a}}$ & $5^{\mathrm{a}}$ & $6^{\underline{a}}$ & $7^{\mathrm{a}}$ & $8^{\underline{a}}$ \\
\hline$T 1^{*}$ & $2,9 a$ & $8,3 a$ & $21,3 a$ & $7,0 \mathrm{~b}$ & $15,2 \mathrm{~b}$ & $23,1 \mathrm{~b}$ & $11,8 \mathrm{~b}$ & $21,1 \mathrm{a}$ \\
\hline T2 & $2,7 a$ & $8,6 \mathrm{a}$ & $21,2 \mathrm{a}$ & $5,0 a$ & $14,5 \mathrm{a}$ & $21,3 b$ & $11,4 \mathrm{~b}$ & $20,6 a$ \\
\hline T3 & $1,9 a$ & $7,9 a$ & $20,0 a$ & $5,7 a$ & $13,6 \mathrm{a}$ & $21,0 \mathrm{~b}$ & $9,8 a$ & $21,4 \mathrm{a}$ \\
\hline T4 & $2,2 \mathrm{a}$ & $7,5 \mathrm{a}$ & $20,7 a$ & $5,1 \mathrm{a}$ & $12,6 a$ & $18,8 \mathrm{a}$ & $10,4 a$ & $21,1 \mathrm{a}$ \\
\hline T5 & $2,9 a$ & $9,2 \mathrm{a}$ & $21,9 a$ & $7,7 \mathrm{~b}$ & $16,1 \mathrm{~b}$ & $22,7 \mathrm{~b}$ & $12,9 \mathrm{~b}$ & $22,4 a$ \\
\hline CV (\%) & 57,93 & 23,04 & 11,35 & 24,59 & 16,34 & 11,94 & 17,00 & 9,55 \\
\hline
\end{tabular}

Médias seguidas de mesma letra na coluna não diferem entre si pelo teste de Scott-Knott, a nível de $5 \%$ de probabilidade. *T1: testemunha negativa; T2: silicato de alumínio (R1 + R4); T3: silicato de alumínio (V5 + R1 + R4); T4: silicato de alumínio (V5 + R1 + R4 + R5.1); T5: testemunha positiva - trifloxistrobina + protioconazol (R1 + R4).

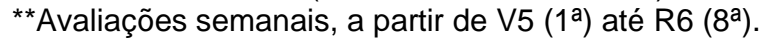

O possível efeito aditivo foi verificado principalmente para $C$. includens em função de sua localização na planta, pois prefere o terço inferior e com isto fica menos exposta à ação dos produtos fitossanitários. A dose de silício utilizada não foi suficiente para reduzir sua população, mas como sugerido por EPSTEIN (1994), MARSCHNER (1995), DANNON \& WYDRA (2004) e BRAGA et al. (2009), este elemento pode ter proporcionado a formação de barreiras mecânicas ou alterado as respostas bioquímicas da planta ao ataque dos insetos, com aumento da síntese de toxinas, reduzindo a disponibilidade de alimento e possivelmente facilitando a ação do inseticida por proporcionar algum tipo de estresse nas lagartas. 
De acordo com NERI et al. (2005), o silício pode ser utilizado no Manejo Integrado de Pragas, haja visto, que a integração de silício e inseticida é positiva em relação ao inseticida isolado. Novas pesquisas verificando possibilidades de utilização conjunta de silício e inseticidas devem ser conduzidas, principalmente com menores doses de inseticidas para facilitar a ação de agentes de controle biológico.

\section{CONCLUSÃO}

A aplicação de silicato de alumínio foi capaz de reduzir a severidade da ferrugem asiática da soja.

A cultivar CD 2737 RR foi menos suscetível à ferrugem asiática em relação a Anta 82 RR.

A produtividade de grãos aumentou com três e quatro aplicações de silicato de alumínio.

A aplicação de silicato de alumínio não afetou a população de lagartas desfolhadoras, porém, constatou-se efeito aditivo quando empregado com inseticida.

\section{REFERÊNCIAS}

BRAGA FT et al. 2009. Características anatômicas de mudas de morangueiro micropropagadas com diferentes fontes de silício. Pesquisa Agropecuária Brasileira 44: 128-132.

CAMPBELL CL \& MADDEN LV. 1990. Introduction to plant disease epidemiology. New York: Jonh Wiley \& Sons. 532p.

CONAB. 2017. Companhia Nacional de Abastecimento. Acompanhamento da safra brasileira de grãos. Brasília: CONAB 4: 118-130.

CRUSCIOL CAC et al. 2013. Aplicação foliar de ácido silícico estabilizado na soja, feijão e amendoim. Revista Ciência Agronômica 44: 404-410.

CRUZ MFA et al. 2013. Inducers of resistance and silicon on the activity of defense enzymes in the soybean-Phakopsora pachyrhizi interaction. Bragantia 72: 162-172.

DANNON EA \& WYDRA K. 2004. Interaction between silicon amendment, bacterial wilt development and phenotype of Ralstonia solanacearum in tomato genotypes. Physiological and Molecular Plant Pathology 64: 233-243.

EPSTEIN E. 1994. The anomaly of silicon in plant biology. Proceedings National of Academy Science of the United State of America 91: 11-17.

FRAC. 2017. Fungicide Resistance Action Committee. Informação sobre carboxamidas em ferrugem da soja. Disponível em: http://media.wix.com/ugd/85b1d3_060a6876562140b693f03708057acff2.pdf. Acesso em: 18 mar. 2017.

FREITAS BUENO RCO et al. 2011. Lepidopteran larva consumption of soybean foliage: basis for developing multiplespecies economic thresholds for pest management decisions. Pest Management Science 67: 170-174.

GODOY CV et al. 2006. Diagrammatic scale for assessment of soybean rust severity. Fitopatologia Brasileira 31: 63-68.

GODOY CV et al. 2016. Asian soybean rust in Brazil: past, present, and future. Pesquisa Agropecuária Brasileira 51: 407-421.

GOELLNER K et al. 2010. Phakopsora pachyrhizi, the causal agent of Asian soybean rust. Molecular Plant Pathology 11: 169-177.

GOUSSAIN MM et al. 2002. Efeito da aplicação de silício em plantas de milho no desenvolvimento biológico da lagartado-cartucho Spodoptera frugiperda (J.E.Smith) (Lepidoptera: Noctuidae). Neotropical Entomology 31: 305-310.

HARTMAN GL et al. 2015. Compendium of soybean diseases and pests. 5.ed. St. Paul: The American Phytopathological Society. p.56-58.

HIRANO M et al. 2010 Validação de escala diagramática para estimativa de desfolha provocada pela ferrugem asiática em soja. Summa Phytopathologica 36: 248-250.

LIMA LM et al. 2010. Quantificação da ferrugem asiática e aspectos nutricionais de soja suprida com silício em solução nutritiva. Summa Phytopathologica 36: 51-56.

LIMA SF et al. 2012. Efeito da semeadura em linhas cruzadas sobre a produtividade de grãos e a severidade da ferrugem asiática da soja. Bioscience Journal 28: 954-962.

MADALOSSO MG et al. 2010. Cultivares, espaçamento entrelinhas e programas de aplicação de fungicidas no controle de Phakopsora pachyrhizi Sidow em soja. Ciência Rural 40: 2256-2261.

MARSCHNER H. 1995. Mineral nutrition of higher plants. 2.ed. New York: Academic Press. 889p.

MEDEIROS AM \& PERUCH LAM. 2012. Fungicidas e argila silicatada o controle da antracnose maracujá amarelo. Semina 33: 1803-1808.

MOREIRA AR et al. 2010. Resposta da cultura de soja a aplicação de silício foliar. Bioscience Journal 26: 413-423.

NAVARINI L et al. 2007. Controle químico da ferrugem asiática (Phakopsora pachyrhizi Sidow) na cultura da soja. Summa Phytopathologica 33: 182-186.

NERI DKP et al. 2005. Interação silício com inseticida regulador de crescimento no manejo da lagarta-do-cartucho Spodoptera frugiperda (J. E. Smith, 1797) (Lepidoptera: Noctuidae) em milho. Ciência e Agrotecnologia 29: 11671174.

OLIVEIRA ACB \& ROSA APSA. 2014. Indicações técnicas para a cultura da soja no Rio Grande do Sul e em Santa Catarina, safras 2013/2014 e 2014/2015. Pelotas: Embrapa. 124p. (Documentos 382).

PELUZIO JM et al. 2002. Influência do desfolhamento artificial no rendimento de grãos e componentes de produção da soja [Glycine max (L.) Merrill]. Ciência e Agrotecnologia 26: 1197-1203.

PEREIRA SC et al. 2009. Aplicação foliar de silício na resistência da soja à ferrugem e na atividade de enzimas de 
defesa. Tropical Plant Pathology 34: 164-170.

PESHIN R \& DHAWAN AK. 2009. Integrated pes management: Inovation-development process. Dordrecht: Springer. $628 p$.

POZZA EA et al. 2015. Silicon in plant disease control. Revista Ceres 62: 323-331.

SCHURT DA et al. 2013. Silício alterando compostos derivados da pirólise de bainhas foliares de plantas de arroz infectadas por Rhizoctonia solani. Bragantia 72: 52-60.

SILVA AJ et al. 2013. Haste verde e retenção foliar na cultura da soja. Summa Phytopathologica 39: 151-156.

SOSA-GÓMEZ DR \& OMOTO C. 2012. Resistência a inseticidas e outros agentes de controle em artrópodes associados à cultura da soja. In: HOFFMANN-CAMPO CB et al. Soja - Manejo Integrado de Insetos e outros Artrópodes-Praga. Brasília: Embrapa. p.673-723.

SOUZA PV et al. 2014. Chrysodeixis includens (Lepidoptero: Noctuidae) on soybean treated with resistance inducers. African Journal of Biotechnology 13: 4562-4567.

STÜRMER GR et al. 2014. Eficiência do pano-de-batida na amostragem de insetos-pragas de soja em diferentes espaçamentos entre linhas e cultivares. Semina 35: 1177-1186.

TEIXEIRA IR et al. 2008. Fontes de silício em cultivares de feijão nas safras das águas e da seca. Revista Ciência Agronômica 39: 562-568. 